\title{
The Role of Parental Citizenship Status on Depression of U.S. Citizen Children
}

\author{
Alissa Bey, ${ }^{* 1}$ Marsha Norton ${ }^{2}$ \\ Faculty: Rhonda K. Lewis ${ }^{1}$ \\ ${ }^{1}$ Department of Psychology, Fairmount College of Liberal Arts \& Sciences \\ ${ }^{2}$ Department of Aging Studies, Fairmount College of Liberal Arts \& Sciences
}

INTRODUCTION: Roughly 50,000,000 Hispanic/LatinX immigrant individuals reside in the U.S. and that number is projected to continue growing throughout the next decade (Guitirez, 2012). As of 2016 about 11 million of the immigrants in the United States were undocumented. Past literature supports that there is a link between parental citizenship status and the physical and mental health outcomes of their children (Vargas \& Ybarra, 2017; Hainmueller, 2017; Landale, Hardie, Oropesa, \& Hillemeier, 2015).

PURPOSE: The purpose of this study is to compare depression scores between three groups of Hispanic/Latinx U.S. citizen children 1) who have both parents who are U.S. citizens 2) who have one parent who is a U.S. citizen, and 3) who have neither parent who is a U.S. citizen.

MethoDs: Data from Wave I of the Children of Immigrants Longitudinal Study (CILS) from 1992 was used to answer the research questions. A total of 835 participants were included in this study. The Center of Epidemiology Studies Depression Scale (CES-D) was used to assess depression scores among this population of Hispanic/Latinx children. Self-reported citizenship status of the mother and father was categorized into three groups: both parents U.S. citizens, one parent U.S. citizen, neither parent U.S. citizen.

RESULTS: The results showed that the depression scores of children who have both parents who are U.S. citizens significantly differs from the depression scores of children who have one parent who is a U.S. citizen. Children who have one parent who is a U.S. citizen have an average depression score that is .07 higher than those who have both parents who are U.S. citizens.

CONCLUSION: This study provides evidence that depression in children may be impacted by their parents' immigration status, especially when only parent is a U.S. citizen. 